\title{
Spatial Variation of Soil Available Phosphorous in the Dal Lake Catchment of Lesser Himalayas
}

\author{
Mushtaq A. Wani ${ }^{1}$, Zahid M. Wani ${ }^{2}$ \\ ${ }^{1}$ Division of Soil Science, SKUAST-Kashmir, Shalimar, Srinagar, Jammu and Kashmir, India \\ ${ }^{2}$ Faculty of Remote Sensing and GIS, School of Engineering and Technology, Asian Institute of Technology, Bangkok, Thailand
}

Email address:

mushtaqb4u@gmail.com (M. A. Wani), zahidwani87@gmail.com (Z. M. Wani)

\section{To cite this article:}

Mushtaq A. Wani, Zahid M. Wani. Spatial Variation of Soil Available Phosphorous in the Dal Lake Catchment of Lesser Himalayas. International Journal of Environmental Monitoring and Analysis. Vol. 3, No. 5, 2015, pp. 364-372. doi: 10.11648/j.ijema.20150305.29

\begin{abstract}
The study attempts to evaluate the spatial pattern of soil available phosphorus, and its availability with respect to various factors including elevation, slope and landuse using statistical methods and GIS spatial analysis techniques. The results showed that the Ordinary Kriging Spherical method performed the best in the prediction of soil available phosphorus in the Dal Lake catchment. The spatial variation of soil available phosphorus was high in Dal Lake catchment and the upstream regions around Dal Lake, including the north of Dal Lake, had the highest soil available phosphorus content. The mean and standard deviation of soil available phosphorus content gradually decreased as the slope increased. The cultivated land comprised $24.36 \%$ of the catchment and out of that land $50.81 \%$ belonged to the medium to very high SAP level classes, and it played a major role in SAP availability within the catchment and a potential source of phosphorus to Dal Lake resulting in eutrophication. Among land use types, paddy fields have some of the highest maximum values and variation of coefficients. Sub watershed scale soil available phosphorus was significantly affected by elevation, slope and landuse and was decided by not only these environmental factors but also some other factors such as artificial phosphorus fertilizer application.
\end{abstract}

Keywords: Soil Available Phosphorous, Spatial Distribution, Environmental Factor, Dal Lake Catchment

\section{Introduction}

Eutrophication, associated with discharge of nitrogen and phosphorus into water from point- and nonpoint-sources, has become a severe water pollution problem in many countries (Li et al., 2009; Smith, et al., 1999 and Sherwood and Qualls, 2001). Dal Lake, one of the freshwater lakes in India, is located in the center of Kashmir Province, India $\left(74.826^{\circ}-74.881^{\circ} \mathrm{E}\right.$ and $\left.34.084^{\circ}-34.147^{\circ} \mathrm{N}\right)$. Over the last two decades, with the population growth and the rapid economic development in the drainage area, nutrient-rich effluents have increasingly discharged into the lake. This has resulted in severe contamination and eutrophication of this lake. In 2000, Dal Lake's water was moderately polluted, with a nutritional status of moderate eutrophication and the major pollution indicators were total phosphorus, total nitrogen and sulphate. The pollution was mainly from agricultural land, horticulture areas and domestic wastewater. The spatial variation analyses of soil available phosphorous are needed to better understand the distribution and transport of catchment nonpoint-source phosphorus across landscapes to better inform how we can manage land use activities such as precision fertilization and nutrient-based agricultural partition management to minimize environmental impacts such as lake eutrophication.

In recent decades, with the development of Geographic Information System (GIS), Global Positioning System (GPS) and Remote Sensing (RS) technology, the spatial distribution of soil available phosphorus as an important soil quality indicator has gradually become an international research focus and it has been introduced into the agricultural resources and ecological management by a variety of governments in many counties including India. Today different geostatistical and GIS spatial analysis techniques are used widely for prediction of spatial variations of the soil properties. Robinson and Metternicht used three different techniques including Inverse Distance Weight (IDW), cokriging and spline methods for predicting the level of soil salinity, acidity and organic matter in South West of Australia and the results showed that the cokriging and spline methods were the best techniques for estimation of the soil salinity level and organic matter content. Results also showed that the IDW method was suitable for prediction of soil acidity level (Zare-Mehrjardi, 2010 and 
Robinson and Metternicht, 2006). Wani et al. (2010) studied the spatial variability of soil micronutrient content in submerged areas of Baramulla district, India. Yamashita et al. (2010) investigated the seasonal and spatial variation of nitrogen dynamics in the litter and surface soil layers along a slope in a tropical dry evergreen forest in northeastern Thailand. Wani et al. (2014) examined the spatial patterns of soil nutrient ( $\mathrm{Zn}, \mathrm{Fe}, \mathrm{Cu}$ and $\mathrm{Mn}$ ) using geostatistical analysis in different soils in agricultural landscape in district Kupwara. Wani et al. (2015) quantified the spatial variation of surficial $(0-15 \mathrm{~cm})$ soil micronutrients within agricultural areas in northern district, India. Lin et al. (2007) evaluated the phosphorus storage and the phosphorus density of paddy soils and characterized the spatial variations of phosphorus among the subgroups of paddy soils and soil regions in China. Page et al. (2005) investigated the soil $\mathrm{P}$ status, distribution, and variability, both spatially and with soil depth, of two different first-order catchments; and determined variation in soil $\mathrm{P}$ concentration in relation to catchment topography (quantified as the "topographic index") and critical source areas.

However, very little research on the spatial distribution of soil available phosphorus and total phosphorus has been conducted in the Dal Lake catchment. In this paper, the spatial variation of soil available phosphorus and its availability with environmental factors in the Dal Lake catchment were analyzed using statistical methods and GIS spatial analysis techniques.

\section{Materials and Methods}

\subsection{Study Area}

The Dal Lake catchment is located west of Zabarwan Mountain and north of the Jehlum River in the north India and central Kashmir Province (Figure 1). The catchment is wide from north to south and narrow from east to south. Its area extends from $74^{\circ} 36^{\prime} 36.71^{\prime \prime}$ to $75^{\circ} 12^{\prime} 53.57^{\prime \prime} \mathrm{E}$ and $34^{\circ} 03^{\prime} 50.8^{\prime \prime}$ to $34^{\circ} 27^{\prime} 57.5^{\prime \prime} \mathrm{N}$, and the drainage area of the Dal Lake catchment occupies about $1492.09 \mathrm{~km}^{2}$, with a water area of about $16.2 \mathrm{~km}^{2}$. This catchment area has a typical temperate climate type, the yearly mean temperature is between -5 to $33^{0}$ $\mathrm{C}$, with an average of $16.5^{\circ} \mathrm{C}$. The annual precipitation is in the $680-1000 \mathrm{~mm}$, with an average of approximately $760 \mathrm{~mm}$. Undulating terrain characterizes the topography surrounded by Zabarwan Mountain, Dara Mountain and Dachigam Mountain. Elevations vary from about 1578 to 2,433 m with an average of around $1710 \mathrm{~m}$. The rivers in the Dal Lake catchment show a Dal Lake-centered radial distribution because of the terrain conditions. There is a high-density of stream networks with a total of thirteen streams in the catchment, including Telbal stream, Dachigam stream, Batapora stream, Shalimar stream, Nishat stream, Brein stream, Cheshma Shahi stream, Dalgate stream, etc.

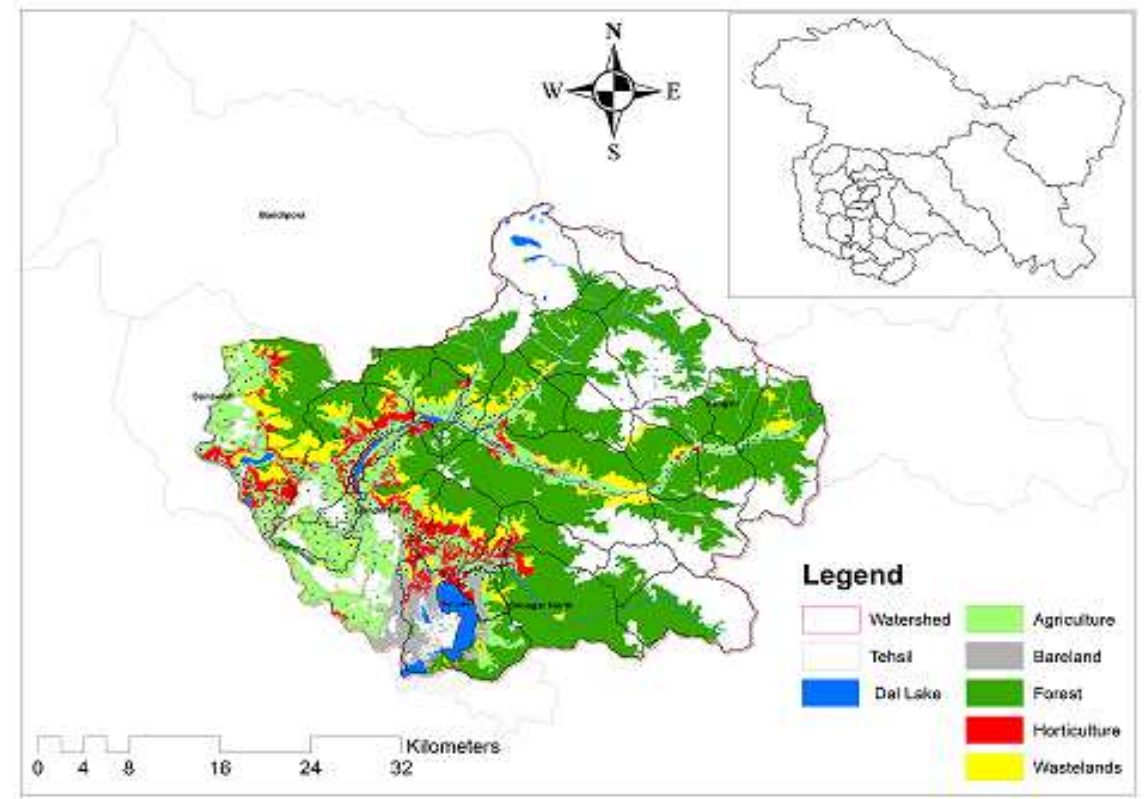

Figure 1. Location of the Dal Lake catchment in Kashmir Province, India and the sampling sites of soil available phosphorous and sub watersheds in the Dal Lake catchment.

\subsection{Surface Soil Survey}

\subsubsection{Sampling Sites}

In this study, a total of three hundred twenty seven (327) random soil sampling sites were set up, as shown in Figure 1. Samples were taken at depths from 0 to $0.2 \mathrm{~m}$ depth. Among them, there were ninety one sampling sites in Ganderbal tehsil, seventy six in Kangan tehsil, seventy three in Lar tehsil, twenty eight in Sonawari tehsil and thirty nine in north Srinagar tehsil.

\subsubsection{Laboratory Analysis}

The soil samples were taken for laboratory analysis. In laboratory, the soil samples were air-dried and passed through a $2 \mathrm{~mm}$ sieve before analysis, and the Olsen and Sommers method (1982) was used to measure the soil available phosphorus of the three hundred twenty seven soil samples. 


\subsection{Spatial Interpolation and Validation}

Interpolation is a mathematical function that estimates the values at locations where no measured values are available. In this paper, a total of four commonly used spatial interpolation methods, including the deterministic interpolation methods of IDW, and the stochastic method of ordinary kriging with spherical, exponential, Gaussian (or normal distribution) semivariogram model, were used to predict the spatial distribution of soil available phosphorus in the Dal Lake catchment based on the soil samples. IDW method interpolates a surface from points using an inverse distance weighted (IDW) technique. In interpolation with IDW method, a weight is attributed to the point to be measured. The amount of this weight is dependent on the distance of the point to another unknown point (Zare-Mehrjardi, 2010). Kriging method interpolates a surface from points using kriging, and kriging is a processor-intensive process. When the kriging method is set to Ordinary, the available semivariogram models are spherical, exponential and Gaussian (ESRI, 2011). The grid cell resolution of the predicted soil available phosphorus was 30 meters. Among the 327 soil samples, 307 random samples (Figure 1) were used for the interpolation, and the remaining 20 samples for model validation.

Table 1. Description of the statistics used in assessing the model performance.

\begin{tabular}{lll}
\hline Statistical variable & Description & Equation \\
\hline$<\mathrm{O}>$ & $\begin{array}{l}\text { Mean of the observed } \\
\text { variable }\end{array}$ & $\frac{1}{n} \sum_{i=1}^{n} O_{i}$ \\
$<\mathrm{P}>$ & $\begin{array}{l}\text { Mean of the } \\
\text { model-predicted variable }\end{array}$ & $\frac{1}{n} \sum_{i=1}^{n} \mathrm{P}_{i}$ \\
$\mathrm{MD}$ & Mean difference & $\frac{1}{n} \sum_{i=1}^{n}\left(O_{i}-\mathrm{P}_{i}\right)$ \\
$\mathrm{MAD}$ & Mean absolute difference & $\frac{1}{n} \sum_{i=1}^{n}\left|O_{i}-\mathrm{P}_{i}\right|$ \\
$\mathrm{MAPD}$ & $\begin{array}{l}\text { Mean absolute percent } \\
\text { difference }\end{array}$ & $\left.\frac{100}{<O>}\left|\frac{1}{n} \sum_{i=1}^{n}\right| O_{i}-\mathrm{P}_{i} \mid\right]$ \\
\hline
\end{tabular}

$\mathrm{n}$ represents the number of observations

The performance of the four methods was evaluated using true validation including scatter plots and regression statistics, which involved comparison of predictions of soil available phosphorus at the remaining twenty samples for model validation with their corresponding observed values. The effectiveness of each method was assessed using five indicators, including the mean of the observed variable $(<\mathrm{O}>)$, the mean of the model-predicted variable $(<\mathrm{P}>)$, the mean difference (MD), the mean absolute difference (MAD), and the mean absolute percent difference (MAPD) as shown in Table 1, from the measured and predicted values (Timmermans et al., 2007).

\subsection{Spatial Variation Analysis Method}

The analysis included the spatial pattern of soil available phosphorus, level delineation of soil available phosphorus content and its spatial distribution, soil available phosphorus under different elevation and slope, and soil available phosphorus under different land use. The analysis methods included the use of GIS spatial analysis and statistical analysis, and the analysis software included EXCEL, SPSS and ARCGIS. The involved data included the original soil available phosphorus content of 327 samples, predicted soil available phosphorus spatial data interpolated by ordinary Kriging Spherical method, Digital Elevation Model (DEM), slope and land use type map. The soil available phosphorus attributes were analyzed using descriptive statistical analysis by calculating the mean, maximum, minimum, range, standard deviation, coefficient of variation, and area percentage.

\subsection{Analysis Method of Relation}

Sub watersheds were used as basic calculation units for the relation analysis between soil available phosphorus and environment factors including elevation, slope, and landuse. The data included DEM, land use map and slope map. In this paper, the $30 \mathrm{~m}$ SRTM DEM data was used to delineate the sub watersheds in the Dal Lake catchment. A catchment analysis on the terrain model for the Dal Lake was performed to generate data on flow direction, flow accumulation, stream definition, stream segmentation, and watershed delineation using hydrology analysis tool. After the above several processing steps and further revised according to DEM and the rivers distribution, 13 sub watersheds (Figure 1) were obtained based on surface drainage patterns. Then the $13 \mathrm{sub}$ watersheds in the Dal Lake catchment were selected as the basic calculation units for each factor. Based on the raster data of environmental factors and soil available phosphorus, their spatial distribution maps were produced using Zonal Statistics Tool which calculated statistics on values of each raster within the 13 sub watersheds. Then the average values of sub watershed scale soil available phosphorus and environment factors were input to SPSS software for further analysis. The relation analysis methods included the correlation analysis, one-way analysis of variance (ANOVA), multiple compare (LSD) and multiple regression analysis.

\section{Results and Discussion}

\subsection{Validation of Interpolation Results}

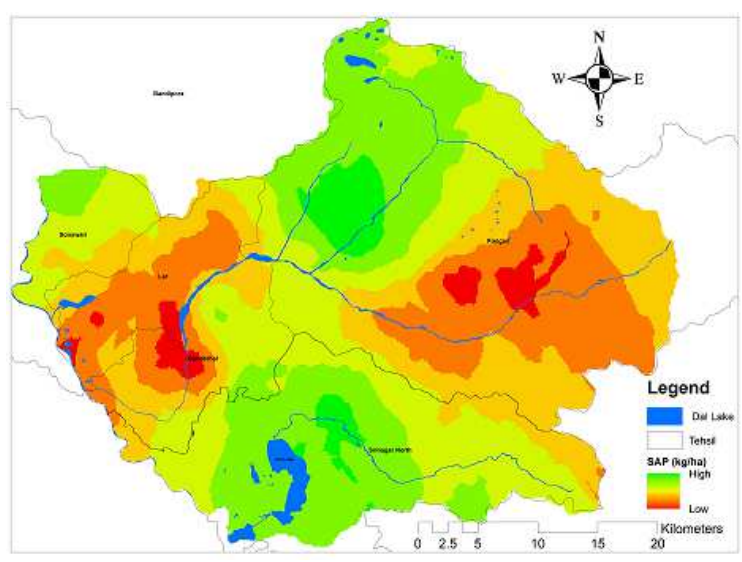

(a) 


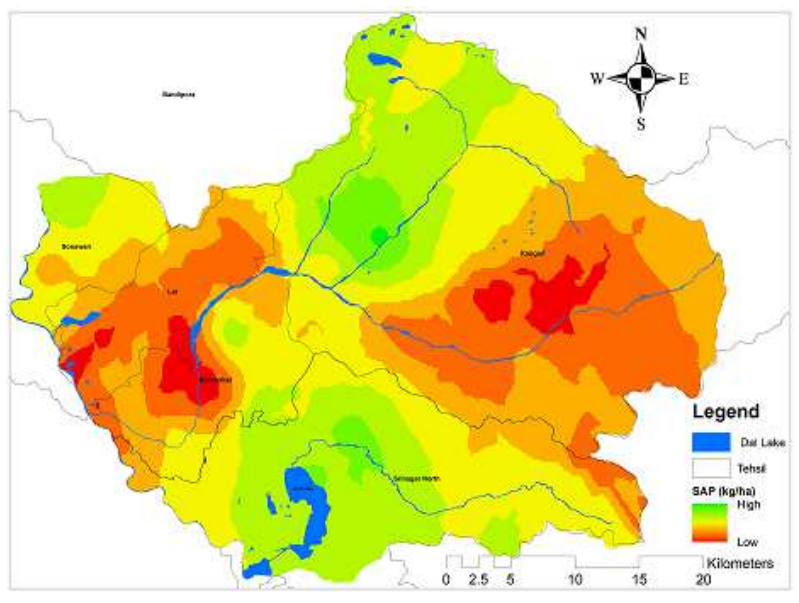

(b)

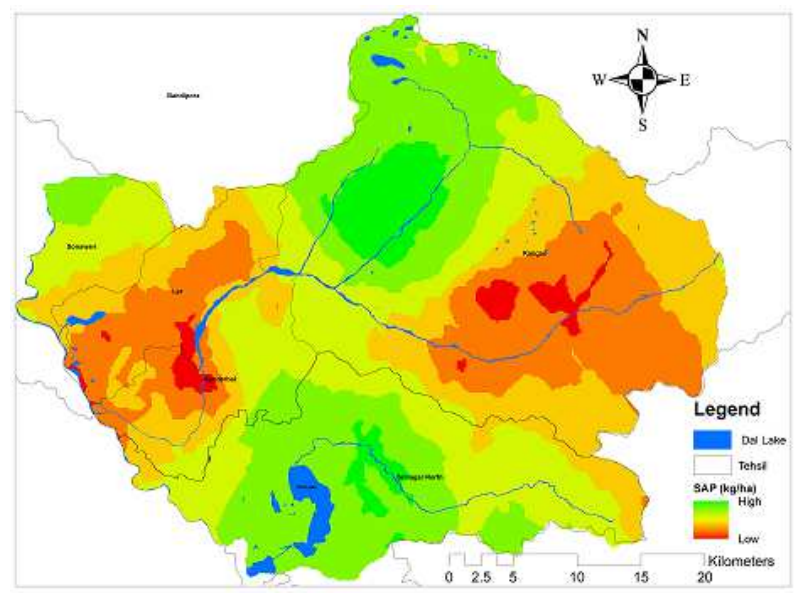

(c)

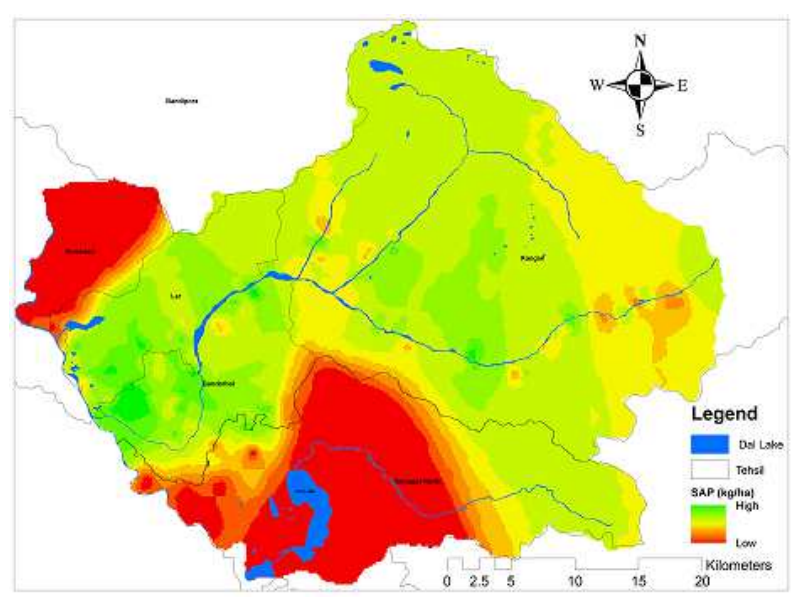

(d)

Figure 2. Predicted soil available phosphorus using (a) Ordinary Kriging Spherical (b) Ordinary Kriging Exponential (c) Ordinary Kriging Gaussian (d) IDW methods.

Different methods have different capabilities to reflect the spatial distributions of soil available phosphorus (Figure 2). In order to quantitatively compare the differences of soil available phosphorus values predicted using the four spatial interpolation methods, a correlation analysis between the remaining twenty observed and predicted values was performed and the correlation coefficients listed in Table 2. The results showed that the predicted soil available phosphorus using Ordinary Kriging Spherical method was in best correlation with the observed values, and the correlation coefficient reached 0.838 . The predicted soil available phosphorus using Kriging Ordinary Gaussian method was in worst correlation with the observed values, and the correlation coefficient reached only 0.331 .

Table 2. Descriptive statistics and Pearson correlation coefficient between the observed and predicted soil available phosphorus values using different interpolation methods.

\begin{tabular}{lllll}
\hline Particulars & $\begin{array}{l}\text { Ordinary } \\
\text { Kriging } \\
\text { Spherical }\end{array}$ & $\begin{array}{l}\text { Ordinary } \\
\text { Kriging } \\
\text { Exponential }\end{array}$ & $\begin{array}{l}\text { Ordinary } \\
\text { Kriging } \\
\text { Gaussian }\end{array}$ & IDW \\
\hline $\begin{array}{l}\text { Mean } \\
\text { Root mean } \\
\text { square }\end{array}$ & 0.064 & 0.052 & 0.132 & 1.096 \\
$\begin{array}{l}\text { Mean } \\
\text { standardized }\end{array}$ & 0.002 & 0.001 & 21.273 & 20.404 \\
$\begin{array}{l}\text { Root mean } \\
\text { square }\end{array}$ & 1.038 & 1.070 & 0.006 & - \\
$\begin{array}{l}\text { standardized } \\
\text { Average }\end{array}$ & 20.549 & 20.073 & 21.269 & - \\
$\begin{array}{l}\text { standard error } \\
\text { Correlation }\end{array}$ & 0.838 & 0.789 & 0.331 & - \\
$\begin{array}{l}\text { coefficient } \\
\text { Regression }\end{array}$ & 0.380 & 0.391 & 0.359 & 0.706 \\
$\begin{array}{l}\text { Coefficient } \\
\text { Y-intercept }\end{array}$ & 18.712 & 18.425 & 19.438 & 13.452 \\
\hline
\end{tabular}

Then the predicted soil available phosphorus values using the six spatial interpolation methods were plotted against the ten observed samples values, and the 1:1 lines were also plotted in the graphs (Figure 3). In Figure 3, the dashed lines corresponds to the $1: 1$ relation and the solid lines to the regression equations and the predicted using Ordinary Kriging Gaussian method versus observed soil available phosphorus values had the biggest decisive coefficient $(\mathrm{R}=0.291)$. The slope of the line in Figure 3 (c) fitted to the predicted and observed soil available phosphorus values was 0.294 and differed from 1, and the y-intercept was 21.635 and differed from zero, indicating that the Ordinary Kriging Gaussian method underestimated the lowest values and overestimated the highest values compared to the observed values.

For further evaluation of the differences of soil available phosphorus values estimated using the four methods, several statistics suggested by Willmott (1982) and used by Timmermans et al., 2007 listed in Table 1, were used to compare the estimation results, and the comparison between the predicted and observed soil available phosphorus values was tabulated in Table 3. From the results in Table 3, it can be seen that the mean of the observed variable was $30.36 \mathrm{~kg} \mathrm{ha}^{-1}$, while the mean of the Ordinary Kriging Spherical model-predicted variable was $30.41 \mathrm{~kg} \mathrm{ha}^{-1}$, and their difference was only $0.052 \mathrm{~kg} \mathrm{ha}^{-1}$. The mean absolute difference (MAD) between the observed and Ordinary Kriging Spherical method-predicted values was $15.46 \mathrm{~kg} \mathrm{ha}^{-1}$. Comparison of the values estimated by different methods in Table 3 suggests that the values of the mean of the 
model-predicted variable, mean difference, mean absolute difference, mean absolute percent difference increase in order as Ordinary Kriging Exponential, Ordinary Kriging Spherical, Ordinary Kriging Gaussian and IDW, respectively. This implies that Ordinary Kriging Spherical method performed the best and then followed by the Ordinary Kriging Exponential method in second, Ordinary Kriging Gaussian method in third and IDW method the worst. So the prediction result by Ordinary Kriging Spherical method was selected to analyze the spatial variation of soil available phosphorous and its availability with environmental factors in the Dal Lake catchment.

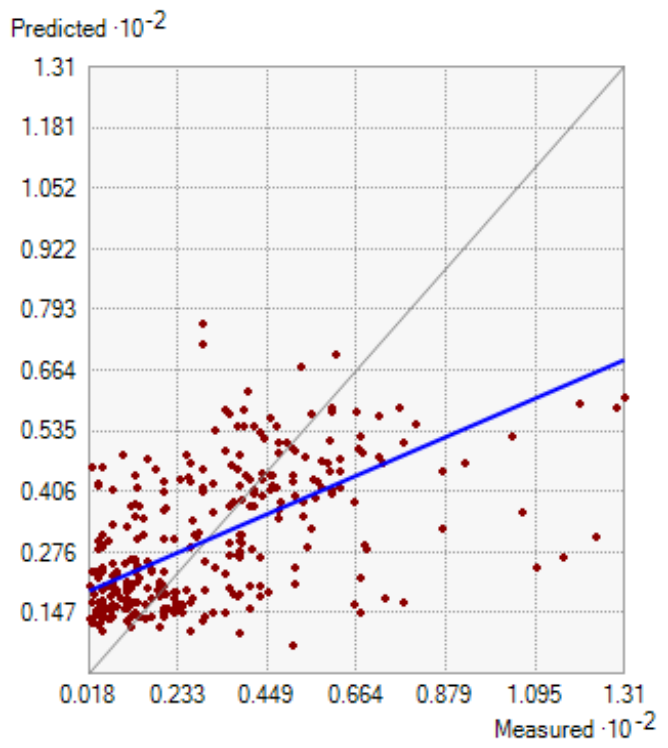

(a)

$$
\left(y=0.319 x+20.726 R^{2}=0.289\right)
$$

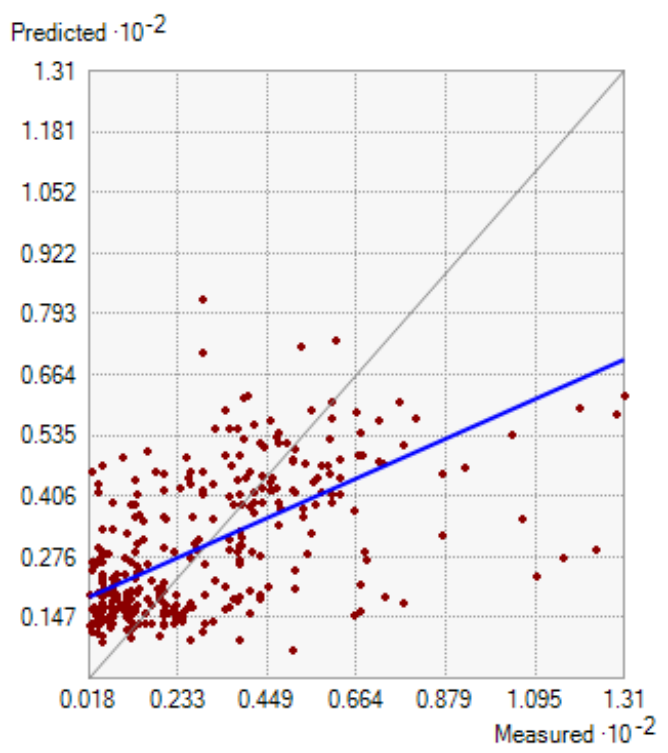

(b)

$\left(y=0.319 x+20.724 R^{2}=0.289\right)$

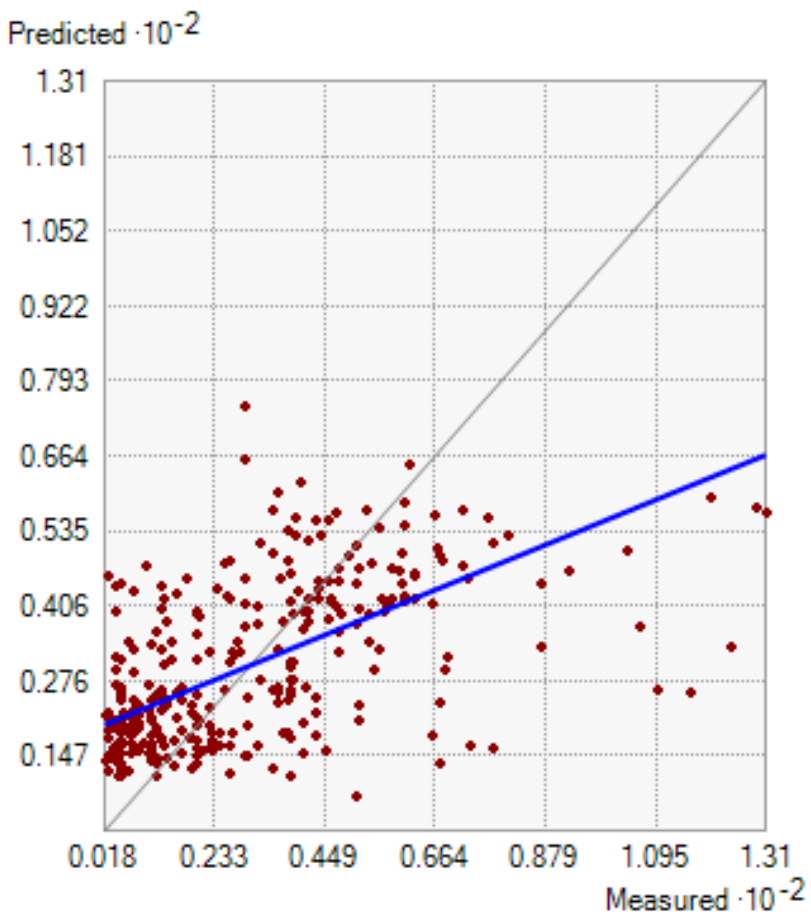

(c)

$\left(y=0.294 x+21.635 R^{2}=0.291\right)$

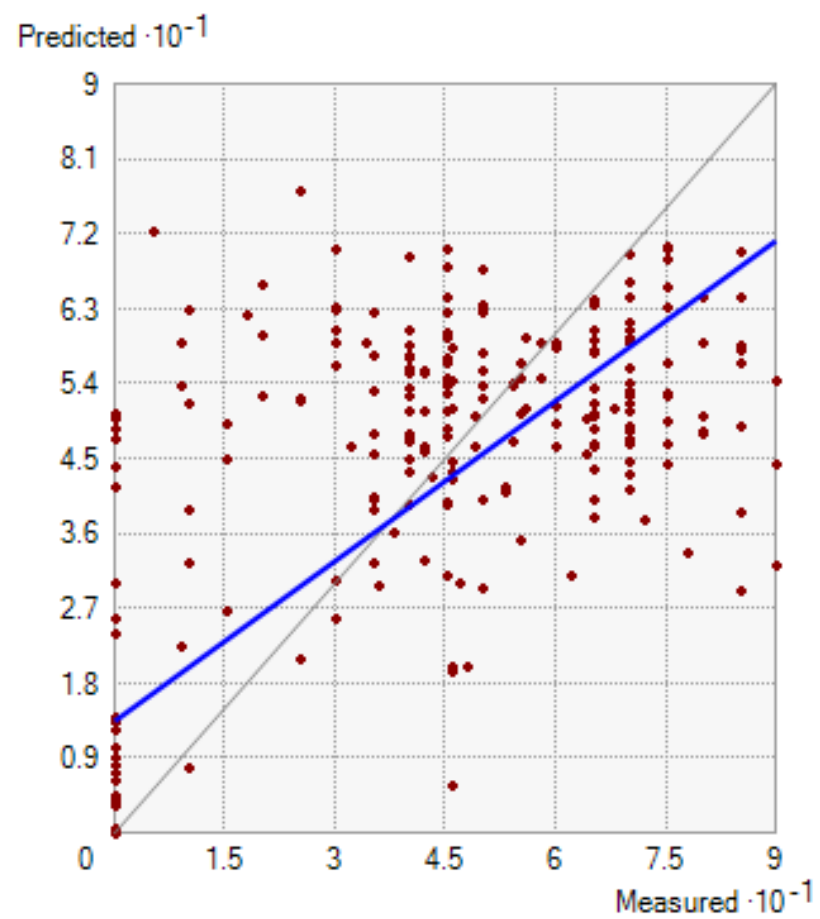

(d)

$\left(y=-0.060 x+46.975 R^{2}=0.008\right)$

Figure 3. Predicted using (a) Kriging Ordinary Spherical (b) Kriging Ordinary Exponential (c) Kriging Ordinary Gaussian (d) IDW methods versus observed soil available phosphorus. 
Table 3. Statistics of model performance for predicting soil available phosphorus.

\begin{tabular}{|c|c|c|c|c|c|}
\hline Method & $<O>\left(\right.$ kg ha $\left.^{-1}\right)$ & $<\mathrm{P}>\left(\mathrm{kg} \mathrm{ha}^{-1}\right)$ & MD $\left(\mathrm{kg} \mathrm{ha}^{-1}\right)$ & MAD $\left(\mathrm{kg} \mathrm{ha}^{-1}\right)$ & MAPD (\%) \\
\hline Ordinary Kriging Spherical & 30.36 & 30.41 & 0.052 & 15.46 & 50.92 \\
\hline Ordinary Kriging Exponential & 30.36 & 30.02 & 0.048 & 15.47 & 50.96 \\
\hline Ordinary Kriging Gaussian & 30.36 & 30.49 & 0.132 & 15.60 & 51.38 \\
\hline IDW & 30.36 & 45.15 & 14.791 & 30.04 & 98.81 \\
\hline
\end{tabular}

IDW $=$ Inverse Distance weighting

\subsection{Spatial Characteristics of Soil Available Phosphorus}

Table 4 represents the summary statistics of soil available phosphorus of predicted watershed-scale and 327 soil samples. According to the statistical values, it can be found that the soil available phosphorus values observed and predicted had similar mean, minimum, maximum, range, standard deviation and variation coefficient values.
For the observed 327 soil samples, the values were between 1.8 and $131.0 \mathrm{~kg} \mathrm{ha}^{-1}$ with an average of $30.36 \mathrm{~kg} \mathrm{ha}^{-1}$, standard deviation of $24.94 \mathrm{~kg} \mathrm{ha}^{-1}$ and variation coefficient of $135.29 \%$. For the result predicted by the IDW method, the values were between 0 and $77.21 \mathrm{~kg} \mathrm{ha}^{-1}$ with an average of $40.21 \mathrm{~kg} \mathrm{ha}^{-1}$, standard deviation of $21.62 \mathrm{~kg} \mathrm{ha}^{-1}$ and variation coefficient of $108.64 \%$.

Table 4. Summary statistics of soil available phosphorus of soil samples and predicted catchment scale.

\begin{tabular}{|c|c|c|c|c|c|c|}
\hline$\overline{\text { Item }}$ & Mean $\left(\mathrm{kgha}^{-1}\right)$ & $\operatorname{Min}\left(\mathrm{kgha}^{-1}\right)$ & $\operatorname{Max}\left(\mathrm{kgha}^{-1}\right)$ & Range $\left(\mathrm{kgha}^{-1}\right)$ & SD $\left(\mathrm{kgha}^{-1}\right)$ & $\overline{C V}(\%)$ \\
\hline Soil samples & 30.36 & 1.80 & 131.00 & 129.20 & 24.94 & 135.29 \\
\hline Catchment scale & 40.21 & 0.00 & 77.21 & 77.21 & 21.62 & 108.64 \\
\hline
\end{tabular}

$\mathrm{SD}=$ Standard Deviation $\mathrm{CV}=$ Coefficient of Variation

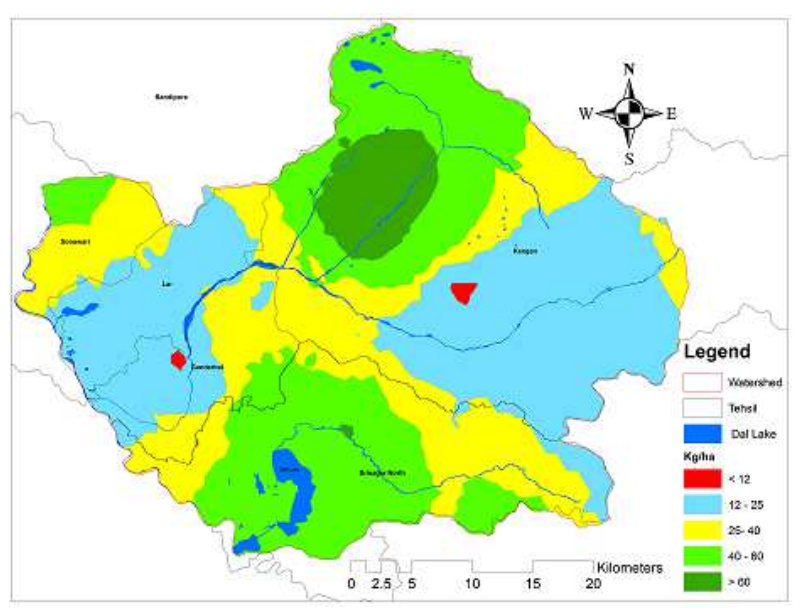

Figure 4. Spatial distribution of soil available phosphorus (SAP) in the Dal Lake Catchment.

According to Figure 4, it can be found that the spatial distributions of soil available phosphorus estimated using the Ordinary Kriging Spherical method with the observed values of 327 soil samples were similar, and the spatial variation of soil available phosphorus in the Dal Lake catchment was high. From the spatial distribution of soil available phosphorus as exhibited in Figure 4, it can be seen that phosphorus was highest to the north of Dal Lake. In addition, the northern part of the Dal Lake catchment, including some area of Kangan tehsil, had a relatively high soil available phosphorus values. In the other regions of the Dal Lake catchment, the soil available phosphorus content was relatively low.

The level delineation results of soil available phosphorus content in the Dal Lake catchment as shown in Table 5 showed that catchment scale soil available phosphorus content was high. Only 0.27 percent of the total catchment area belonged to the very low level, with an average of $6.64 \mathrm{~kg} \mathrm{ha}^{-1} ; 34.56$ percent of the total catchment area belonged to the low level, with an average of $17.49 \mathrm{~kg} \mathrm{ha}^{-1} ; 28.16$ percent of the total watershed area belonged to the medium level, with an average of $33.11 \mathrm{~kg} \mathrm{ha}^{-1} ; 31.66$ percent of the total watershed area belonged to the high level, with an average of $48.46 \mathrm{~kg} \mathrm{ha}^{-1}$; 5.35 percent of the total watershed area belonged to the very high level, with an average of $79.64 \mathrm{~kg} \mathrm{ha}^{-1}$. The very high level had the largest standard deviation $\left(21.71 \mathrm{~kg} \mathrm{ha}^{-1}\right)$ and second largest variation coefficient $(27.27 \%)$, the low level had the smallest standard deviation $\left(3.05 \mathrm{~kg} \mathrm{ha}^{-1}\right)$ and variation coefficient $(18.29 \%)$, very low level had the largest variation coefficient $(45.44 \%)$ and second smallest standard deviation $\left(3.72 \mathrm{~kg} \mathrm{ha}^{-1}\right)$.

Table 5. Summary statistics of soil available phosphorus of different nutrient levels.

\begin{tabular}{|c|c|c|c|c|c|c|c|}
\hline Code & Level range $\left(\mathrm{kgha}^{-1}\right)$ & Level & Area (\%) & $\operatorname{Mean}\left(\mathrm{kgha}^{-1}\right)$ & Range $\left(\mathrm{kgha}^{-1}\right)$ & SD $\left(\mathrm{kgha}^{-1}\right)$ & CV $(\%)$ \\
\hline 1 & $<12$ & Very low & 0.27 & 6.64 & 10.0 & 3.72 & 45.44 \\
\hline 2 & $12-25$ & Low & 34.56 & 17.49 & 11.6 & 3.05 & 18.29 \\
\hline 3 & $25-40$ & Medium & 28.16 & 33.11 & 14.7 & 4.86 & 14.68 \\
\hline 4 & $40-60$ & High & 31.66 & 48.46 & 19.4 & 5.82 & 12.02 \\
\hline 5 & $>60$ & Very high & 5.35 & 79.64 & 71.1 & 21.71 & 27.27 \\
\hline
\end{tabular}




\subsection{Soil Available Phosphorus Under Different Elevation and Slope}

Based on the undulating surface condition in the Dal Lake catchment, it was divided into eight elevation levels (Table 6) and six slope levels (Table 7). Surface elevation ranging from 1578 to 1650 meter belonged the level I region, 1650 to 1750 meter level II region, 1750 to 1850 meter level III region, 1850 to 1950 meter level IV region, 1950 to 2050 meter level V region, 2050 to 2150 meter level VI region, 2150 to 2250 meter level VII region and 2250 to 2450 meter level VIII region. According to the Table 6, it can be found that the soil phosphorus content in level I region ranged from 1.8 to 106.2 $\mathrm{kg} \mathrm{ha}^{-1}$ with an average of $28.47 \mathrm{~kg} \mathrm{ha}^{-1}$, in level II region ranged from 1.8 to $116.3 \mathrm{~kg} \mathrm{ha}^{-1}$ with an average of $34.47 \mathrm{~kg}$ $\mathrm{ha}^{-1}$, in level III region ranged from 4.0 to $124.1 \mathrm{~kg} \mathrm{ha}^{-1}$ with an average of $37.01 \mathrm{~kg} \mathrm{ha}^{-1}$, in level IV region ranged from 4.0 to $60.4 \mathrm{~kg} \mathrm{ha}^{-1}$ with an average of $26.08 \mathrm{~kg} \mathrm{ha}^{-1}$, in level V region ranged from 2.4 to $131.0 \mathrm{~kg} \mathrm{ha}^{-1}$ with an average of $58.49 \mathrm{~kg} \mathrm{ha}^{-1}$, in level VI region ranged from 4.6 to $120.0 \mathrm{~kg}$ $\mathrm{ha}^{-1}$ with an average of $27.80 \mathrm{~kg} \mathrm{ha}^{-1}$, in level VII region ranged from 4.6 to $22.5 \mathrm{~kg} \mathrm{ha}^{-1}$ with an average of $13.23 \mathrm{~kg}$ $\mathrm{ha}^{-1}$ and in level VIII region ranged from 7.4 to $42.9 \mathrm{~kg} \mathrm{ha}^{-1}$ with an average of $27.70 \mathrm{~kg} \mathrm{ha}^{-1}$. It can also be found that the mean and standard deviation of soil available phosphorus content does not show any trend with the increase in elevation. And the variation coefficient in the level VI region was largest, amounting to $99.26 \%$, but in the level VII region smallest, only $49.29 \%$. However, the variation coefficients in level II and III regions accounting for the most of the catchment area were also large, and they reached $82.97 \%$ and $89.89 \%$ respectively. In level III and V regions, the soil available phosphorus contents were high. This is mainly because that the regions were dominated by paddy fields. And the level III region was dominated by bareland, so its soil available phosphorus content was also relative high. However, the level VII and VIII regions were dominated by forest land. They had lower soil available phosphorus contents because of no artificial phosphorus fertilizer application there.

Table 6. Summary statistics of soil available phosphorus of different elevation levels.

\begin{tabular}{|c|c|c|c|c|c|c|c|}
\hline Code & Elevation range (m) & Area (\%) & Min (kgha-1) & Max (kgha-1) & Mean (kgha-1) & SD (kg ha-1) & CV (\%) \\
\hline I & $1578-1650$ & 24.98 & 1.8 & 106.2 & 28.47 & 22.0 & 77.28 \\
\hline II & $1650-1750$ & 9.89 & 1.8 & 116.3 & 34.47 & 28.61 & 82.97 \\
\hline III & $1750-1850$ & 9.49 & 4.0 & 124.1 & 37.01 & 33.30 & 89.89 \\
\hline IV & $1850-1950$ & 10.03 & 4.0 & 60.4 & 26.08 & 20.97 & 79.92 \\
\hline V & $1950-2050$ & 17.57 & 2.4 & 131.0 & 58.49 & 46.30 & 79.04 \\
\hline VI & $2050-2150$ & 23.83 & 4.6 & 120.0 & 27.80 & 27.60 & 99.26 \\
\hline VIII & $2250-2450$ & 2.78 & 7.4 & 42.9 & 27.70 & 14.78 & 53.35 \\
\hline
\end{tabular}

Table 7. Summary statistics of soil available phosphorus of different levels of slope.

\begin{tabular}{|c|c|c|c|c|c|c|c|}
\hline Code & Slope range (degree) & Area (\%) & Min (kgha-1) & Max (kgha-1) & Mean (kgha-1) & SD (kgha-1) & CV (\%) \\
\hline I & $0-3$ & 17.36 & 4.00 & 120.00 & 39.90 & 37.59 & 94.21 \\
\hline II & $3-5$ & 7.58 & 2.40 & 124.10 & 32.92 & 29.13 & 88.49 \\
\hline III & $5-8$ & 8.51 & 2.40 & 128.80 & 32.37 & 28.19 & 87.09 \\
\hline IV & $8-15$ & 11.88 & 1.80 & 131.00 & 31.15 & 25.89 & 83.11 \\
\hline V & $15-25$ & 7.81 & 1.80 & 80.50 & 29.80 & 19.46 & 65.30 \\
\hline VI & $25-73$ & 46.85 & 19.40 & 42.90 & 25.90 & 16.62 & 64.17 \\
\hline
\end{tabular}

Table 8. Summary statistics of soil available phosphorus of different land use types.

\begin{tabular}{|c|c|c|c|c|c|c|c|}
\hline Code & Area (\%) & Min (kgha-1) & Max (kgha-1) & Mean (kgha-1) & Range (kgha-1) & SD (kgha-1) & CV (\%) \\
\hline I & 9.38 & 2.4 & 131.0 & 41.09 & 128.6 & 39.09 & 95.13 \\
\hline II & 5.61 & 5.2 & 109.7 & 35.85 & 104.5 & 40.71 & 113.57 \\
\hline III & 60.66 & 7.4 & 67.0 & 36.03 & 59.6 & 17.98 & 49.90 \\
\hline IV & 5.97 & 3.0 & 56.0 & 24.63 & 53.0 & 18.36 & 74.53 \\
\hline $\mathrm{V}$ & 18.39 & 1.8 & 124.1 & 29.63 & 131.8 & 24.19 & 81.64 \\
\hline
\end{tabular}

$\mathrm{I}=$ agriculture, $\mathrm{II}=$ bareland, $\mathrm{III}=$ forest, $\mathrm{IV}=$ horticulture, $\mathrm{V}=$ wasteland

Surface slope ranging from 0 to 3 degree belonged the level I region, 3 to 5 degree level II region, 5 to 8 degree level III region, 8 to 15 degree level IV region, 15 to 25 degree level V region and 25 to 73.01 degree level VI region. According to the Table 7 , it can be found that the mean and standard deviation of soil available phosphorus content gradually decreased while the slope increased. The variation coefficient in the level I region was largest, amounting to $94.21 \%$, but in the level VI region smallest, only $64.17 \%$. However, the variation coefficients in level II, III, IV and $\mathrm{V}$ regions accounting for the most of the catchment area were also large, and they reached $88.49 \%, 87.09 \%, 83.11 \%$ and $65.30 \%$, 
respectively. In level I region, the soil available phosphorus contents was the highest. The land use type in the area mainly consisted of cultivated land including paddy fields and bareland, and the vegetation cover was composed mainly of rice and mustard and the popular cultivation mode was rice-sarson rotation. However, the level III, IV, V and VI regions had relatively large slope. The areas were dominated mainly by forest land and had the lowest soil available phosphorus contents. Most parts of the level VI region located at the junction of hills, mountains and plains, soil available phosphorus content in the area was relatively low.

\subsection{Soil Available Phosphorus under Different Land Use}

In this paper, only the soil available phosphorus in cultivated land (agriculture and horticulture), forest land, and bareland was included in the analyses. According to Table 8 and Figure 5, it can be found that the agriculture had the largest soil available phosphorus content with an average of $41.09 \mathrm{~kg} \mathrm{ha}^{-1}$, forest land the second largest with an average of $36.03 \mathrm{~kg} \mathrm{ha}^{-1}$. The horticulture had the smallest soil available phosphorus content with an average of only 24.63 $\mathrm{kg} \mathrm{ha}^{-1}$, wasteland the second smallest with an average of $29.63 \mathrm{~kg} \mathrm{ha}^{-1}$.

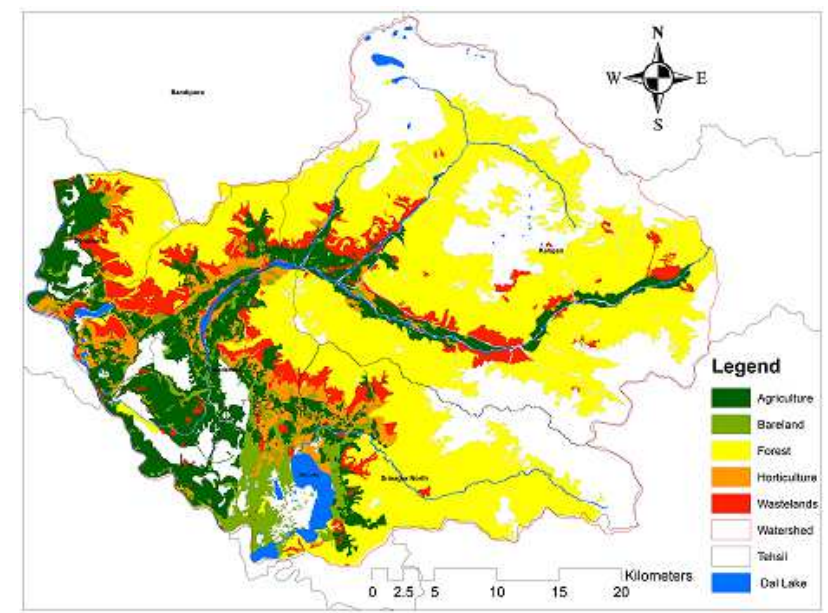

Figure 5. Spatial distribution of soil available phosphorus levels in different land use types.

Comparison of the mean values in Table 8 suggests that the soil available phosphorus values increased in order as agriculture, forest land, bareland, wasteland and horticulture, respectively. According to the variation coefficient of soil available phosphorus in different land use types, it can be found that four kinds of land use types, bareland, agriculture, wasteland, horticulture had the largest variation coefficient, we can also see that agriculture fields have some of the highest maximum values and variation of coefficients. It indicates that human fertilization had a significant impact on soil available phosphorus content. Figure 5 represents the spatial distribution of soil available phosphorus levels in different land use types. According to the spatial distribution of cultivated land and soil available phosphorus (Figure 5), it can be found that only 0.27 percent of the total cultivated land area belonged to the low level, 34.56 percent the low level, 28.16 percent the medium level, 31.66 percent the high level, 5.35 percent the very high level. It thus seems clear that cultivated land played a major role in SAP availability within the catchment and a potential source of phosphorus in Dal Lake, resulting in eutrophication.

\section{Conclusion}

Based on the study on spatial variation of soil available phosphorous in the Dal Lake catchment, the following three conclusions were obtained:

1) In the prediction of soil available phosphorus in the Dal lake catchment, the Ordinary Kriging Spherical method performed the best and then followed by the Ordinary Kriging Exponential in second, Kriging Ordinary Gaussian method in third and IDW method the worst.

2) The spatial variation of soil available phosphorus was high in the Dal Lake catchment. The upstream regions around Dal Lake, including the north of Dal Lake had the highest soil available phosphorus content.

3) The mean and standard deviation of soil available phosphorus content gradually decreased as the slope increased. The region ranging from 0 to 3 degrees of slope was dominated by cultivated land and had the highest soil available phosphorus content, the regions ranging from 25 - 73.01 degrees of slope were dominated by forest land and had the lowest soil available phosphorus contents. The cultivated land belonged to the medium to very high SAP level classes, and it played a major role in SAP availability within the watershed and a potential source of phosphorus to Dal Lake, resulting in eutrophication. Among the land use types, paddy fields have some of the highest maximum values and variation of coefficients.

\section{Acknowledgements}

The author greatly acknowledges the Jammu and Kashmir State Council for Science and Technology, Government of Jammu and Kashmir for financial support of this study.

\section{References}

[1] Environmental Systems Research Institute, Inc (ESRI). ArcGIS Desktop Help 9.2; ESRI: Redlands, CA, USA, 2007. Available

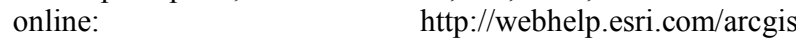
desktop/9.2/index.cfm?Topic Name=welcome (accessed on 20 July 2011).

[2] Li, M.; Wu, Y.J.; Yu, Z.L.; Sheng, G.P.; Yu, H.Q. Enhanced nitrogen and phosphorus removal from eutrophic lake water by Ipomoea aquatica with low-energy ion implantation. Water Res. 2009, 43, 1247-1256.

[3] Lin, J.S.; Shi, X.Z.; Lu, X.X.; Yu, D.S.; Wang, H.J.; Zhao, Y.C.; Sun, W.X. Storage and spatial variation of phosphorus in paddy soils of China. Pedosphere, 2007, 19, 790-798. 
[4] Olsen, S.R.; Sommers, L.E. Phosphorus. In Methods of Soil Analysis: Chemical and Microbiological Properties; Page, A.L., Ed.; ASA and SSSA: Madison, WI, USA, 1982, pp. 403-430.

[5] Page, T.; Haygarth, P.M.; Beven, K.J.; Joynes, A.; Butler, T.; Keeler, C.; Freer, J.; Wwens P.N.; Wood, G.A. Spatial variability of soil phosphorus in relation to the topographic index and critical source areas: sampling for assessing risk to water quality. J. Environ. Qual., 2005, 34, 2263-2277.

[6] Robinson, T.P.; Metternicht, G. Testing the performance of spatial interpolation techniques for mapping soil properties. Comput. Electron. Agr., 2006, 50, 97-108.

[7] Sherwood, L.J.; Qualls, R.G. Stability of phosphorus within a wetland soil following ferric chloride treatment to control eutrophication. Environ. Sci. Technol., 2001, 35, 4126-4131.

[8] Smith, V.H.; Tilman, G.D.; Nekola, J.C. Eutrophication: Impacts of excess nutrient inputs on freshwater, marine, and terrestrial ecosystem. Environ. Pollut. 1999, 100, 179-196.

[9] Timmermans, W.J.; Kustas, W.P.; Anderson, M.C.; French, A.N An intercomparison of the surface energy balance algorithm for land SEBAL and the two-source energy balance TSEB modeling schemes. Rem. Sens. Environ. 2007, 108, 369-384.

[10] Wani, Mushtaq A., Zahid Mushtaq and Shaista Nazir. Mapping of micronutrients of the submerged rice soils of Kashmir. Research Journal of Agricultural Sciences, 2010, 1(4): 458-462.
[11] Wani, Mushtaq A., Wani, Zahid, M., Bhat, M.A., Kirmani, N.A. and Shaista, N. Mapping of DTPA extractable cationic micronutrients in soils under rice-and maize ecosystems of Kupwara district in Kashmir-A GIS approach. Journal of the Indian Society of Soil Science, 2014, 62:351-359.

[12] Wani, Mushtaq A., Wani Zahid M., Shaista, N., Kirmani, N.A. and Bhat, M.A. Spatial Variability of DTPA Extractable Cationic Micronutrients in Northern Part of Lesser Himalayas using GIS Approach. Research Journal of Agricultural Sciences, 2015, 6:8-14.

[13] Willmott, C.J. Some comments on the evaluation of model performance. Bull. Am. Meteorol. Soc. 1982, 63, 1309-1313.

[14] Yamashita, N.; Ohta, S.; Sase, H.; Luangjame, J.; Visaratana, T.; Kievuttinon, B.; Garivait, H.; Kanzaki, M. Seasonal and spatial variation of nitrogen dynamics in the litter and surface soil layers on a tropical dry evergreen forest slope. Forest Ecol. Manag, 2010, 259, 1502-1512.

[15] Zare-Mehrjardi, M.; Taghizadeh-Mehrjardi, R.; Akbarzadeh, A Evaluation of geostatistical techniques for mapping spatial distribution of soil $\mathrm{pH}$, salinity and plant cover affected by environmental factors in Southern Iran. Not. Sci. Biol. 2010, 2, 92-103. 